\title{
Unicentric castleman's disease of neck node in old age- rare presentation of a rare disease
}

\author{
Gopalakrishnan MP1 ${ }^{1}$, Nizarudeen $\mathrm{A}^{2}$ \\ ${ }^{1}$ Dr. Midhun. P. Gopalakrishnan, Senior Resident, ${ }^{2}$ Dr. A. Nizarudeen, Additional Professor; both authors are affiliated \\ with Department of General Surgery, Government TD Medical College, Alappuzha, Kerala, India.
}

Address for Correspondence: Dr. Midhun. P. Gopalakrishnan, Senior Resident in General Surgery, Government TD Medical College, Alappuzha, Kerala. E-mail : drmidhungopalakrishnan@gmail.com

\begin{abstract}
Castleman's disease is an uncommon lymphoproliferative disorder that may be unicentric or multicentric disease. We are reporting a case of 75 year old female presented with left level 3 cervical lymph node, whose final diagnosis was unicentric castleman's disease. This presentation is uncommon because unicentric castleman's disease is usually seen in younger adults and it usually affects lymph nodes in chest or abdomen. People with localized Castleman's disease are usually cured by surgical removal of the affected lymph nodes.
\end{abstract}

Keywords: Unicentric, Castleman's Disease, Neck Node, Old Age

\section{Introduction}

Castleman's disease is an uncommon lymphoproliferative disorder that may be unicentric or multicentric disease. It must be distinguished from reactive lymph node hyperplasia and malignancies. They are non cancerous growths that may develop in the lymph node tissue at a single site or throughout the body. It involves hyper proliferation of certain B cells that often produce cytokines. It was named after Dr. Benjamin Castleman who first described it in 1956 [1].
Only a few cases of unicentric Castleman's disease affecting solely neck has been reported in literature $[2,3]$. We are reporting a case of 75 year old female presented with left level 3 cervical lymph node, whose final diagnosis was unicentric castleman's disease confined to that neck node only. This presentation is uncommon because unicentric castleman's disease is usually seen in younger adults and it usually affects lymph nodes in chest or abdomen.

\section{Case Report}

75 year old female presented with swelling neck suggestive of level 3 firm discrete non tender lymph node of size $2 * 2$ $\mathrm{cm}$. There was no lymph node enlargement in other areas. Also there was no hepatosplenomegaly or any other masses palpable per abdomen. General investigations done were within lower limits except for elevated ESR. FNAC reported as presence of inflammatory cells with atypia.

Excision of the lymph node was done and the histopathological report was hyaline vascular variant of Castleman's disease with intrafolicular (Fig 1) and vascular hyalinisation (Fig 2) with lymphocytic infiltration. After getting the pathological report contrast enhanced CT scan of thorax, abdomen and pelvis was taken to complete the work up and it was normal. This case was discussed in our Institutional tumour board after literature review.

Considering her age and the unicentric type of disease, the decision was to keep her under follow up. There is no recurrence of disease after six months of follow up.

Manuscript received: $7^{\text {th }}$ February 2017

Reviewed: $15^{\text {th }}$ February 2017

Author Corrected: $23^{\text {rd }}$ February 2017

Accepted for Publication: $28^{\text {th }}$ February 2017 


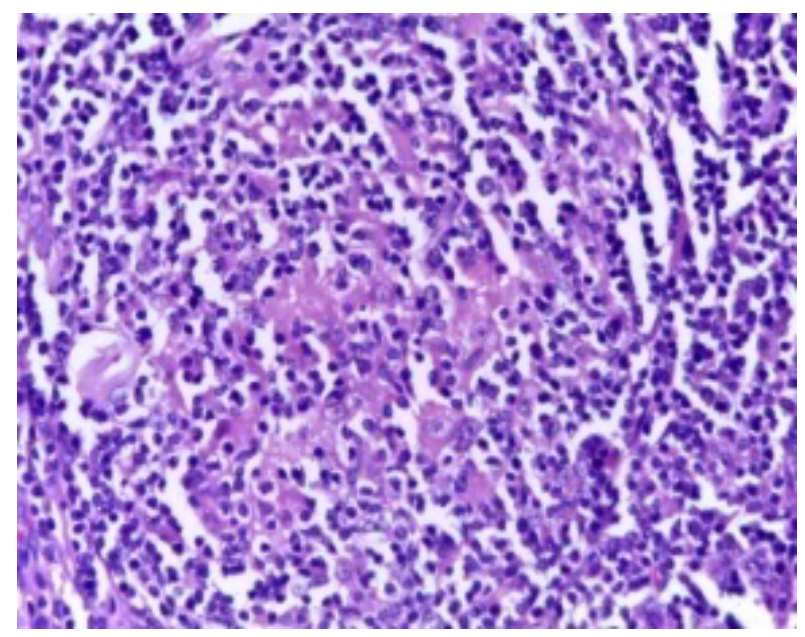

Fig-1: High power view showing int rafolicular hyalinization

\section{Discussion}

There are two main types of Castleman's disease.

1. Unicentric or localised disease [4]

- It affects a single group of lymph nodes.

- Most often it affects lymph node in chest or abdomen.

- People with localised Castleman's disease are usually cured with surgical removal of affected lymph nodes.

2. Multicentric Castleman's disease [5]

- It affects more than a single group of lymph nodes.

- It can also affect other organs containing lymphoid tissue.

- About $50 \%$ of multicentric Castleman's disease is caused by HHV- 8 virus.

- This form sometimes occurs in people infected with HIV.

- People with multicentric Castleman disease often have problems such as serious infections, fever weight loss, fatigue, night sweats and nerve damage that can cause weakness and numbness.

Microscopic sub types are [6]

I. Hyaline vascular variant

- It is the most common type.

- It tends to be localised but in rare cases it is multicentric.

II. Plasma cell Variant.

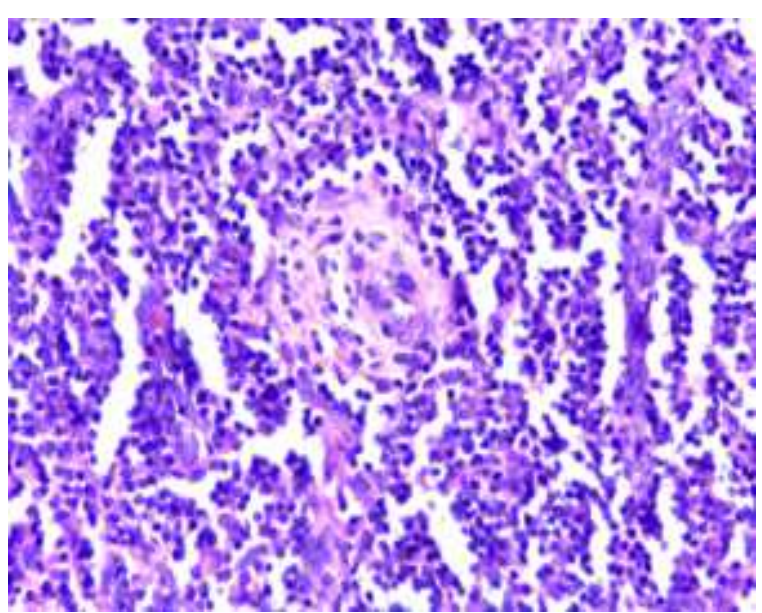

Fig-2: High power view showing vascular hyalinisation

It is slightly more likely to be multicentric, but it is sometimes localised. Castleman's disease can affect children as well as adults. Younger people are more likely to have the localised form. Older adults and those with HIV infection are mostly affected by multicentric form of Castleman's disease. Treatment of unicentric localised form includes either surgical excision or radiotherapy [7]. Multicentric form is treated by combination of corticosteroids, chemotherapy, immunomodulatory agents, monoclonal antibodies etc. There is no definite protocol for treatment of multicentric disease as it being a rare disease only one randomized control study is available for the same [8]. That was based on the use of siltuximab, a chimeric monoclonal antibody against Interleukin - 6 .

\section{Conclusion}

Though Castleman's disease is an uncommon lymphoproliferative disorder, it should be kept in mind as a differential diagnosis of enlarged neck nodes. For unicentric variety local treatment is effective but due to the rarity of the disease no definite treatment protocol is there for multicentric Castleman's disease and it carries poor prognosis.

\section{Funding: Nil, Conflict of interest: None. Permission of IRB: Yes}

\section{References}

1. Aslı Gul Akgul, Bedrettin Yildizeli, Mustafa Yuksel. Castleman's Disease. Marmara Medical Journal. 2005; 18(2): 81-83. 
2. Lin CY, Huang TC. Cervical posterior triangle castleman's disease in a child - case report \& literature review. Chang Gung Med J. 2011 Jul-Aug;34(4):435-9.

3. Zawawi F, Varshney R, Haegert DG, Daniel SJ. Castleman's Disease: a rare finding in a pediatric neck. Int J Pediatr Otorhinolaryngol. 2014 Feb;78(2):370-2. doi: 10.1016/j.ijporl.2013.11.015. Epub 2013 Nov 25.

4. Renuka. S. Melkundi, K C Prasad, Roshan R Jalisatgi, Gautham Swami, Abhilasha Karunasagar. Journal of Clinical and Diagnostic Research. 2015 Apr; 9(4): MD03-MD04.

5. Marcelin AG, Aaron L, Mateus C, et al. Rituximab therapy for HIV-associated Castleman disease. Blood. 2003 Oct 15; 102(8): 2786-8. Epub 2003 Jul 3. DOI: $10.1182 /$ blood-2003-03-0951

6. Ghosh A, Pradhan S V, Talwar C P. Castleman's disease - hyaline vascular type. Clinical, cytological and histological features with review of literature. Indian Journal of Pathology. 2010 Apr-Jun; 53 (2): 244-7.

7. Bowne WB, Lewis JJ, Filippa DA, Niesvizky R, Brooks AD, Burt ME, Brennan MF. The management of unicentric and multicentric Castleman's disease: a report of 16 cases and a review of the literature. Cancer. 1999 Feb 1;85(3):706-17.

8. van Rhee F, Wong RS, Munshi N, Rossi JF, Ke XY, Fosså A, Simpson D, Capra M, Liu T, Hsieh RK, Goh YT, Zhu J, Cho SG, Ren H, Cavet J, Bandekar R, Rothman M, Puchalski TA, Reddy M, van de Velde H, Vermeulen J, Casper C. Siltuximab for multicentric Castleman's disease: a randomised, double-blind, placebo-controlled trial. Lancet Oncol. 2014 Aug;15 (9): 966-74. doi: 10. 1016 /S1470-2045 (14) 70319-5. Epub 2014 Jul 17.

\section{How to cite this article?}

Gopalakrishnan MP, Nizarudeen A. Unicentric castleman's disease of neck node in old age- rare presentation of a rare disease. Int J Med Res Rev 2017;5(02):209-211 doi:10.17511/ijmrr. 2017.i02.17. 